\title{
INFORMATION \& COMMUNICATION TECHNOLOGY PENETRATION INTO EDUCATION: SOME THOUGHTS
}

\author{
Vincentas Lamanauskas \\ University of Šiauliai, Lithuania \\ E-mail: v.lamanauskas@ef.su.It
}

Over the last decade the spread of information communication technologies has been growing very rapidly both in quantitative and qualitative meaning. Not only new, innovative technologies, but also various people communication forms based on these technologies have appeared. Here, it is spoken about so-called social networking websites. Their rapid development raises certain anxiousness as well. Education, as one of society life spheres, can't stay apart. The penetration of technologies in education is very great. The number of computers and computer technologies is expanding not only in educational offices, but also in the environment of every of us: homes, working places and so on. The youth is a very receptive group of society in this respect, seeking to try the newest technologies as quickly as possible. The majority of pupils spend quite a big part of time working on computers and using other computer technologies. It must be accentuated, that very often such kind of activity is not directly related with learning and self-education in a wider sense. It is obvious, that penetration of technologies enables educational community to work differently, to change educational process, to search for new approaches and so on. On the other hand, that raises certain problems and challenges. Though nowadays ICT technologies enable to get, process, save, convey and transmit information very effectively, on the other hand, realisation of information itself becomes problematic. In general, it is obvious that on the one hand, ICT provide quite big possibilities and on the other hand, they cause hard to solve problems. How to find a sensible balance between expectable benefit and probable harm? ICT in education isn't an end in itself, is it? First of all we have to orientate ourselves to effective technology appliance in the educational process seeking better education and self-education quality. Here, ICT competence question remains urgent. It is to do with educators, first of all. Technologies themselves do not improve anything or make effective, do they? It is necessary to be able to use them.

Another visible challenge is a rapid development of technologies themselves. The computer is sought to not only store, analyse and sort out the information in a different way, but also understand it. In this case, it is spoken about qualitatively different work (and communication) with computer. It can be foreseen, that there will be more and more challenges. Already now, it has been accumulated a lot of information, which allows to state that ICT penetration causes negative phenomena as well. This is, first of all, consumer health problems, unsafe and unfavourable working environment questions and so on (pupils very often waste a lot of time searching for information. Some pupils get computer and internet addiction. Pupils' activeness lessens, their health gets worse, they read books less and there is less of live communication). There is an apparent need to teach all level educational process participants the skills of safe computer and internet usage. This is very important for the young school age pupils, whose understanding about possibly negative ICT consequences is inadequate. First of all, teachers and lecturers should have these skills, which they could pass over to pupils and students. In other words, a sensible balance is constantly searched between ICT attractiveness 
PROBLEMS

OF EDUCATION

IN THE $21^{\text {st }}$ CENTURY

Volume 50, 2012

and possible threats, between modernness and real, tangible benefit, between fashion and necessity and inevitability to use them while educating a man. It is worth to mention, that speaking about ICT quite often we use such concepts as faster, easier, simpler, more interesting and so on. However, that does not mean real education yet. School and university shouldn't become a youth entertainment place, where films are demonstrated or other so-called "playful" technologies are used during the lessons and lectures. Such education is sliding along the surface and is only its imitation. Therefore, it would be sensible to state, that both researchers and educational practitioners should pay greater attention to the research and analysis of "side effects" in future. This doesn't mean that disclosure of negative aspects would lessen ICT penetration into education in some way. This is not sought, anyway. However, it is necessary to control and lessen negative consequences in all possible ways.

It is important to emphasize one more moment. Not all ICT which are created have to be used in education. Analysing carried out empiric researches, observing real educational practice, an impression is often made that the use of technologies is as if understandable by itself. However, it is necessary to understand, that not all technologies are being created namely for educational needs. Quite a lot of examples could be given, when created technologies are artificially being tried to transfer into educational environment and into process while in these cases theoretic and empiric substantiation is obviously lacking. In this context, constant teachers and lecturers' sharing of accumulated ICT application experience is necessary. This has to become a part of school (and university) life. As ICT specialists think about possibilities in the nearest future to communicate with computers as with people (Web 3.0), so educators have to constantly think how to apply existing ICT so, that a maximum educational (teaching, educating, training) result would be achieved. Technological educators were not the centre of attention, are not and don't have to be. The centre of attention is a man and his universal education - preparation to be a Man.

Received: November 15, 2012

Accepted: December 10, 2012

Vincentas Lamanauskas $\quad$ PhD., Professor, Siauliai University, Natural Science Education Research Centre, 25-119 P. Višinskio Street, LT- 76351, Siauliai, Lithuania.

E-mail: lamanauskas@lamanauskas.puslapiai.It

Website: http://www.lamanauskas.puslapiai.It 